IP Periodica Polytechnica Civil Engineering

60(2), pp. $189,198,2016$

DOI: $10.3311 /$ PPci.7627

Creative Commons Attribution (1)

RESEARCH ARTICLE

\section{A Risk Assessment Method of Bridge Facilities Damage in the Aspect of Potential Terrorist Attacks}

\author{
Artur Duchaczek, Dariusz Skorupka
}

Received 17-07-2014, revised 03-12-2014, accepted 18-08-2015

\begin{abstract}
The question of terrorism is becoming a principal problem which influences social safety. Terrorist acts are aimed at frightening people and destabilisation of normal functioning of the state. Terrorists are trying to achieve this goal by bombing civilians and public utility facilities including transport system facilities. One of the elements of a transport system is its infrastructure consisting of roads, railways and bridge facilities. This last element encompasses for example bridges, viaducts, flyovers and culverts. Taking into account the fact that bridge facilities are extremely sensitive to terrorist attacks, the authors of this article decided to focus on them in this study. The work presents an original method of damage risk assessment in engineering facilities in the aspect of potential terrorist attacks. The method is based on two selected multi-criteria optimisation methods. The subject of analyses were four selected bridge facilities. The results of the conducted research and analyses were risk assessments of selected bridges. An advantage of the presented solution is the possibility to justify the adopted hierarchy of decision variants. Using the proposed method one can obtain specific numerical values. They can be used in further analyses conducted on a wider scale and to build a hierarchized database of facilities prone to terrorist attacks.
\end{abstract}

\section{Keywords}

crisis management $\cdot$ risk assessment $\cdot$ bridge $\cdot$ construction management $\cdot$ risk management $\cdot$ civil engineering

\section{Artur Duchaczek}

General Tadeusz Kościuszko Military Academy of Land Forces, 109 Czajkowskiego St., 51-150 Wrocław, Poland

e-mail: a.duchaczek@wso.wroc.pl

\section{Dariusz Skorupka}

General Tadeusz Kościuszko Military Academy of Land Forces, 109 Czajkowskiego St., 51-150 Wrocław, Poland

e-mail: d.skorupka@wso.wroc.pl

\section{Introduction}

In normative documents related to crisis situations used in the European Union, a notion of critical infrastructure is used. Critical infrastructure encompasses systems and functional objects related to each other which are a part of these systems, including construction facilities, equipment installations, key services in the security of the state and its citizens as well as effective operation of public administration and institutions and entrepreneurship entities [43].

Critical infrastructure comprises e.g. a transport system, which is responsible for relocation of loads between stationary network elements and logistic systems, such as production plants, warehouses and retail points [25]. One of the elements of the transport system is its infrastructure comprising mainly three basic groups, i.e. roads for all transport branches, transport points and auxiliary equipment used for direct service of roads and transport points [16]. Bridge facilities are always an element of roads and railways. They encompass various types of bridges, viaducts, flyovers, footbridges and culverts. The facilities which are extremely sensitive to terrorist attacks are bridges, this is why they are the subject of this article.

Thus it seems that the development of a quantitative method of risk assessment of a bridge facilities damage will have a utilitarian character because its result will be precious information located on risk maps [43]. A measurable result of the conducted research will be determination of guidelines for the risk assessment of a bridge facilities damage in any selected area of a country [3, 4].

Susceptibility of a given bridge facility to terrorist attacks can be analysed from the perspective of the sensitivity of a given construction to intentional human activity or its significance for the operation of the transport system in a given area of a country [10]. The first approach is supported by American bridge facilities specialists [26, 42], it is based on the knowledge of technical properties of elements in a given construction. This knowledge allows to define weak points in a bridge facility construction and protect them from possible terrorist attacks. The other approach involves assessment of the consequences of a given bridge facility damage, however, this should be a part of the duties of all 
institutions managing transport infrastructure [3, 4].

However, unfortunately both approaches are also used by terrorists. They look for weak points in bridge facilities construction to damage them easily and at the same time they look for facilities whose damage will result in the most serious disturbance of the operation of the existing transport infrastructure in a given area of a country and will involve the biggest media coverage [10].

There are numerous scientific centres dealing with the problems related to bridge facilities design. However, in Poland there is no centre which would conduct research on risk assessment damaging such facilities, with particular consideration for threat conditions such as terrorist attacks. Thus it seems that an additional study of this problem should raise the interest of the scientific environment and organisations responsible for citizens' security.

\section{Risk assessment methods of a bridge facilities dam- age}

The notion of risk in primary sources is understood and defined in a number of ways. Risk is a generally known term and is frequently used by both practitioners and and theoreticians in various areas of human activity. However, similarly to planning, the definition and the way of understanding risk are different. It seems that a descriptive understanding of risk prevails over its quantitative interpretation [30,31].

In practice the notion of risk is understood and defined in various ways. It is understood in a different way by economists who usually focus only on financial aspects and by engineers who refer the issue of risk to machine operation or manufacturing processes disruptions. For example soldiers assess risk related to task performance and policemen treat the notion of risk as a threat to a potential citizen. For ordinary employees risk is often associated with losing work. For this reason it is necessary to develop a clear definition of risk [31].

Regan Sean [29] defines risk as "a probable loss or damage of something or somebody's harm as a result the occurrence of a threat". In his opinion risk is frequently defined as the product of identified factors or events and their influence on a given project A. H. Willet [36] defines risk as "a phenomenon which is objectively correlated with subjective uncertainty related to the occurrence of an undesirable event". Another definition was formed by F. H. Knight [17] considered the classicist of the risk theory and the creator of the measurable and unmeasurable theory. $\mathrm{He}$ claims that "risk is measurable uncertainty and sensu stricte uncertainty is unmeasurable uncertainty " [17]. On the other hand J. Pfeffer [21] defined risk as "a combination of hazard measured with probability while uncertainty is measured with the level of belief".

Natural uncertainty or natural risk is generated by an independent fortuitous event and a natural risk is generated by a fortuitous event related to natural, internal, fortuitous characteristics of physical, chemical, biological, technical, technological, or- ganizational and economic phenomena connected with a given project which are hard to reduce [12]. Model uncertainty and model risk mean risk or uncertainty related to a formal description of engineering and construction projects using models, in the same conditions as the conditions in which fortuitous event occur [12]. Statistical uncertainty or statistical risk directly depends on used statistical methods. Selection of appropriate fortuitous events and a large number performed tests allow to partly eliminate these phenomena [12].

The conducted short analysis shows that the notion of risk is understood and defined in many various ways. It can be assumed even this fact determine the need to examine the issue of risk. Finally in this article for the needs of identification and quantification of risk related to transport infrastructure damage in the aspect of terrorist attacks the following formula was proposed (Eq. (1)).

In the proposed formula, risk $R_{i}$ of terrorist attack occurrence at $i$ bridge facility in a given area of a country is calculated as the product probability $p_{i}$ of the occurrence of this attack and consequences $c_{i}$ resulting from destruction of a particular facility divided by the sum of products $s$ for all $n$ of the analysed bridges [4]:

$$
R_{i}=\frac{p_{i} c_{i}}{s},
$$

where

$$
s=\sum_{i=1}^{n}\left(p_{i} c_{i}\right),
$$

assuming that the value of probability $p_{i}$ and consequences $c_{i}$ is a number in the range $<0 ; 1>$.

Assuming also that the sum of probability $p$ of destructing all bridges equals [4]:

$$
p=\sum_{i=1}^{n} p_{i}=1,
$$

and the sum of consequences $c$ of their destruction is:

$$
c=\sum_{i=1}^{n} c_{i}=1,
$$

risk $R$ of damage of $n$ bridge facilities in the analysed area of a country equals:

$$
R=\sum_{i=1}^{n} R_{i}=1 .
$$

The subject of analyses presented in the article were selected bridges located near Wrocław (Poland - Central Europe). Unusual applications of two selected methods of multicritera optimisation were used to calculate probability $p_{i}$ and consequence $c_{i}$. An advantage of the presented analyses is the fact that the adopted hierarchy of decision variants can be explained scientifically in a simple way, there is no need to refer to one's knowledge, experience and intuition. 
In primary sources numerous methods of multicritera optimisation were presented, they could be used to solve the issue discussed in this article. Authors of numerous works presented both classifications and comparisons of these methods [8, 15], this is why this work does not present this information. According to the authors there are two characteristics which had decisive influence on the selection of these optimisation methods. The first one is the type of variables (linguistic or numerical ones) and the other one was simplicity and clarity of this method.

The type of variables used in the analyses was selected based on criteria adopted by the authors to calculate both probability $p_{i}$ and consequences $c_{i}$. In the case of unmeasurable factors (linguistic variables) the method of Analytical Hierarchy Process (AHP) was used, while in the case measurable factors (numerical variables) the Bellinger method was used. Simplicity and clarity of a given method is very important because it directly influences the will to use this method in engineering practice. Even the best method will not be used by engineers in their everyday professional practice if it is too complex and not very clear. Thus from the point of view of practical applications it will be a "dead" or redundant method.

In this article the method of Analytical Hierarchy Process (AHP) was used to assess the probability of a damage to bridges, whereas the Bellinger method was used to assess the consequences of their damage. The authors are interested only damage to the bridge spans and supports connected with a terrorist attacks.

\section{Assessment of probability of a bridge facility damage in the aspect of terrorist attacks}

\subsection{Theoretical fundamentals of the AHP method}

The AHP method was developed and described by T. L. Saaty [27, 28]. An extensive and clear description of this method can be found also in A. Ostręga's work [20], where the theoretical fundamentals of its application in practical engineering problems are also presented. The procedure of the AHP method was also used by M. Hastak and S. Aury [7] in the development of the ICRAM method. In this article the authors present only the most important theoretical assumptions of the AHP method [5, 14, 20, 24, 35].

By definition the method should facilitate making optimum choices in cases of multicriteria optimisation, and thanks to this reduce them to a series of paired comparisons. This allows to make a numerical measure of validity of the analysed elements [20].

All elements in the decision problem make a hierarchical structure. Thanks to such structure it is possible to focus on a relatively small number of elements at each level. However, the number of elements at a given level should not exceed $7 \pm 2$, because otherwise an inconsequence of comparison could result [20].

Due to the fact that the basis of this method is a pairwise com- parison of each element against one another so standard assessment scales are generally useless. Because of this a 9-point evaluation scale was introduced. Comparing two elements with each other it is possible to establish which of them is preferred and to what extent [24].

In the case of comparisons between elements which do not have measurable character, the so called linguistic approach is used. Then the linguistic variable adopts verbal expressions as its values, they are also limited to a 9-point preference scale [20].

To evaluate elements at particular level of the analysed structure a comparison matrix is created (formula 6), whose order is equal to the number of compared elements [20]:

$$
\mathbf{A}=\left[\begin{array}{cccc}
a_{11}=1 & a_{12} & \ldots & a_{1 n} \\
a_{21}=\frac{1}{a_{12}} & 1 & \ldots & a_{2 n} \\
\ldots & \ldots & \ldots & \ldots \\
a_{n 1}=\frac{1}{a_{1 n}} & 1 & \ldots & a_{m n}
\end{array}\right]
$$

where: $A-$ square matrix containing elements $a_{i j}(i, j=1,2, \ldots, \mathrm{n})$, which are governed by the following principles [20]:

1 if $a_{i j}=z$, then $a_{j i}=\frac{1}{z}, z \neq 0$

2 if criterion $C_{i}$ is equivalent to criterion $C_{j}$, then $a_{i j}=1$ and $a_{j i}=1$, and in particular $a_{i j}=1$ for $i=j$.

Matrix $A$ performs the following property: $a_{i j}>0, a_{i j}=$ $\frac{1}{a_{j i}} \forall i, j=1,2, \ldots n$.

All elements of the analysed model are ordered according to the significance of eigenvector $W=w_{1}, \ldots, w_{n}$, i.e. the higher the value of a eigenvector $W$, the more significant is a given element. To calculate eigenvector $W$ it is necessary to first normalize matrix $A$ (create matrix $B$ ) by dividing each of its elements by a sum of elements in the column in which it is located [20]:

$$
b_{i j}=\frac{a_{i j}}{\sum_{i=1}^{n} a_{i j}} .
$$

Next average values $w_{i}$ are defined for each row of a new matrix $B[20]$ :

$$
w_{i}=\frac{\sum_{j=1}^{n} b_{i j}}{n},
$$

where $i, j=1, \ldots, n$ with $\sum_{i=1}^{n} w_{i}=1$.

In this way the eigenvector $W$ is created, it expresses the evaluation of analysed criteria and variants with regard for the adopted paramount goal. The components of the eigenvector $W$ define the degree to which the lower level elements maintain the property defined at a higher level [20].

A comparison of particular criteria and analysed variants is conducted by defining the degree of preference of one element over the other. It is done by experts on the basis of their, unfortunately, subjective opinions. Regardless of the fact that they have the required knowledge in a given area, they may also make 
mistakes in allocation of marks. This results mainly from lack of consequence in assessment. In the AHP method results credibility is checked by calculation of the consistency index $C I$ and the consistency ratio $C R$. To eliminate any discrepancies also the so called consistency ratio $C R$ is calculated according to the dependence [20]:

$$
C R=\frac{C I}{R I} 100 \%,
$$

where $R I$ is random index, which depends on matrix order $n$, while $C I$ is a consistency index determined from dependence [20]:

$$
C I=\frac{\left(\lambda_{\max }-n\right)}{(n-1)},
$$

where $\lambda_{\max }$ is the largest eigenvalue of a matrix, it is always greater than or equal to the matric order $n$.

The approximate largest eigenvalue of a matrix $\lambda_{\max }$ can be calculated as the value of a sum of averaged in rows products of normalised values of weights and column sums corresponding with particular criteria, which can expressed as follows [5. 14]:

$$
\lambda_{\max }=\sum_{i=1}^{n}\left(w_{i} \sum_{j=1}^{n} a_{i j}\right) .
$$

The rule of logical consistency used in the AHP method is very important. It was assumed that the value of the consistency ratio $C R$ should not exceed $10 \%$. If it takes higher values, the values of dominance degree of one element over the other, allocated during a pairwise comparison of these elements, should be analysed [20].

Presently a lot of variants of the AHP methods have been proposed. Among them there are also variants based on the fuzzy concepts [2, 9, 18, 39]. These papers present a method for decision making under uncertainty. Yang X. et al. [38] also presented comparison of AHP and fuzzy AHP methods. Fuzzy methods allow better use of specialists' experience. For the authors the purpose was to create a simple enough method that would be easy to apply in practice, especially for soldiers. For this reason the work does not include the fuzzy concepts.

\subsection{Criteria taken into account during the probability as- sessment of a bridge facility damage.}

In the determination of the probability of a damage to bridges, it was assumed that it is a value defining one's expectations of a possible occurrence of a given event, in this case a terrorist attack. Thus the value is used to determine the possibility of occurrence of a given event and it takes values of $<0 ; 1>$. It was also assumed that the sum of these numbers (i.e. the total value for all analysed bridge facilities) is always equal to unity. Because probability determination based only on subjective premises and feelings may not be useful in engineering practice, it was necessary to define the method of determination of this probability [3].
Taking into account the assumption that the sum of probability $p$ of destruction of bridge facilities in a given area should be equal to unity, i.e. only one bridge facility will be destructed, and the fact that it is always easier to compare only two variants with each other, particularly that their hierarchy is expressed in linguistic variants, the AHP method was used to define this probability. It was assumed that the probability of a bridge facility damage was equal to the coefficient of a given variant obtained using the AHP method, in this case the variants are all bridge facilities located in a given area (territory). Analysing the possibilities of conducting a terrorist attack on bridge facilities, it was found out that the assessment criteria of probability of damaging such facilities included first of all its localisation and possibility of destructing (damaging) its load-bearing structure. The authors of this study have proposed the adoption of five criteria in the evaluation of probability of a bridge facility damage [3].

In the case of bridge facility location, one should take into account aspect as possibility of protection and defence of a given facility, which is usually related to its distance from a city centre. The first adopted criterion is object security (criterion CP1). It can be assumed that facilities located rather far from a city centre will not be monitored or protected, hence the probability of e.g. earlier mining such a bridge is higher. The second adopted criterion is traffic volume on the bridge (criterion CP2), which is directly related to quality class of the road. When it comes to traffic volume, it seems obvious that a terrorist attack on a bridge is associated with paralysis of communication in the adjacent area of the country, seems a more interesting and more important target for potential terrorists [3].

Details related to the construction of a bridge facility should be analysed taking into account a few aspects, e.g. construction of pillars and spans as well as the type of material used to make them. The next adopted criterion is the length of the analysed span (criterion $C P 3$ ). In the case of bridges with spans longer than $30 \mathrm{~m}$, it is enough to destruct only these spans, in any other case not only spans but also indirect pillars [41].

The material which was used to construct bridges should also be taken into account. These is a four adopted criterion (criterion $C P 4$ ). It was assumed that it was easier to destruct wooden bridges, next stone bridges, concrete, reinforced concrete and steel bridges are the last ones. This results from the fact that steel bridges usually have many more pillar construction elements in comparison with more massive concrete bridges or reinforced steel ones. Generally steel is rather plastic material. In case of equal type of cracks steel is safer than brittle materials, such as for example glass or concrete. The fatigue cracks in structural steel propagate more slowly [3].

The last adopted criterion is construction of a bridge (criterion $C P 5$ ). Analysing only the construction of a bridge one should note that usually suspension bridges and cable-stayed bridges are the most prone to terrorist attacks, next truss and girder bridges (with a small number of girders), at the end of the list there are arch and beam bridges [3]. 
4 Assessment of consequences of a bridge facility damage in the aspect of terrorist attacks

\subsection{Theoretical basis of the Bellinger method}

The Bellinger method was used to assess consequences of transport infrastructure damage, it takes its name from the name of its creator Bernhard Belliner ([1] for research work [19]). It is one of the methods used in multicriteria analysis, it puts elements in order on the basis of the value of combined evaluation determined from a collection of adopted partial criteria [6, 32, 33, 37].

The Bellinger method bases on making decision variant assessment in reference to all criteria comparable, which leads to their subsequent aggregation [32]. Thus for each analysed evaluation criterion of an available decision variant one should establish the most and the least desired state. Next it is necessary to establish if a given criterion is a stimulant or a destimulant of a given decision variant. It is assumed that the difference between states expresses the whole route from one state to another. That is why for each available decision variant evaluation is determined as a fraction of this route in reference to each criterion. It is assumed that a sub-optimum variant is the variant for which the total route is the longest, i.e. the analysed decision variant receives the highest evaluation [37].

A detailed algorithm used in the Bellinger method encompasses eight stages [6]. Calculations are started with definition of requirements and restrictions of the future hypothetical variants of solutions for the analysed problem. Next decision variants available in a given situation, the adopted evaluation criteria, measurement units and the desired direction of changes within a given criterion are defined (the so called stimulants and destimulants). Another element which has to be defined is the top and bottom limit of changes for the analysed partial criteria. After this stage, the hierarchy of particular criteria is established by defining weights attributed to the adopted evaluation criteria. Next a matrix containing the real values of analysed criteria with regard to particular variants is created. At the next stage, the numbers from the table of the earlier stage are presented as a percentage of the route from the least to the most desired state, next the received numbers are multiplied by the earlier adopted weights. At the end of these calculations, on the basis of summed evaluations attributed to particular variants, the best variant is established taking into account all analysed criteria [6].

The presented process of evaluation of decision variants using the Bellinger method can be described by dependencies (Eqs. (12) - 15) presented below. The distance between the top and bottom boundary of a set of values of the $j$-th criterion values of decision variants $\Delta j$ is defined from a dependence [32]:

$$
\Delta j=|\sup X-\inf X|,
$$

where sup $\_X$ is the top boundary of a set of admitted values of the $j$-th criterion, while inf $\_X$ is the bottom boundary of a set of admitted values of the $j$-th criterion values.

The evaluation of the $i$-th decision variant on the basis of the $j$-th criterion of evaluation $o_{x i j}$ is defined for [32]:

- stimulant:

$$
o_{x i j}=\frac{\sup \_X-x_{i}}{\Delta j} \cdot 100 \%,
$$

- destimulant:

$$
o_{x i j}=\frac{\inf X-x_{i}}{\Delta j} \cdot 100 \%,
$$

where $x_{i}$ is a numerical value allocated by an analyst for the $i$-th decision variant, e.g. the length of a bridge span, etc.

The final evaluation of a decision variant is determined on the basis of dependency (15), where the weight of a given criterion or the preference of a decision maker are taken into account [32]:

$$
O_{x i}=\sum_{j=1}^{m} w_{j} o_{x i j},
$$

where $O_{x i}$ is the evaluation of the $i$-th decision variant, while $w_{j}$ is the weight of the $j$-th evaluation criterion (decision maker's preference) by a value in the range $<0,1>$.

\subsection{Criteria taken into account in the evaluation of conse-} quences of a bridge facility damage.

Objectivity of the conducted analyses always depends on the adopted criteria. Due to the fact that bridge facilities are special structures characterised by differentiated constructions, criteria adopted in calculation of their damage risk can be different every time. However, one should be aware that if the number of criteria is too big, it will make conducting the subjective analyses significantly more difficult, and simultaneously will increase the "objectivity" of the obtained only to small extent. The authors of this study have proposed the adoption of five criteria in the evaluation of consequences of a bridge facility damage [4].

The first adopted criterion is the length of a span (criterion $C C 1$ ). It was assumed that the longer a span, the bigger the consequences of its destruction, because reconstruction of an analysed facility is related to time and significant costs. The number of lanes on a bridge was the second criterion (criterion $C C 2$ ). It was assumed that the number of lanes on a bridge has direct influence on destruction consequences. It is related to the fact that in the case of one-way bridges (with a single lane) temporary reconstruction is much easier and faster than in the case of spans with a few lanes [4].

Next the number of indirect pillars was taken into account (criterion $C C 3$ ). In the case of bridges with indirect pillars there is a risk of their destruction which entails additional time and costs related to their possible reconstruction. One of the most important criteria certainly was traffic volume (criterion $C C 4$ ). It is expressed in the number of vehicles passing a span in a 24-hour period, it is also assumed that with the increase in traffic volume on a span, consequences of its destruction are more onerous [4]. 


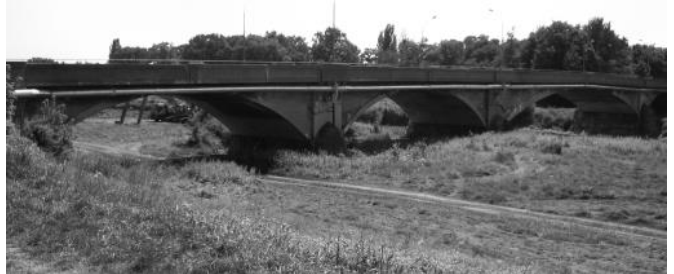

a) Swojczycki Bridge

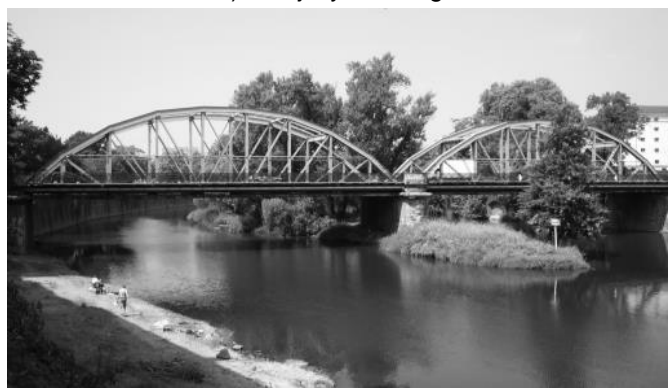

c) Władysław Sikorski Bridge

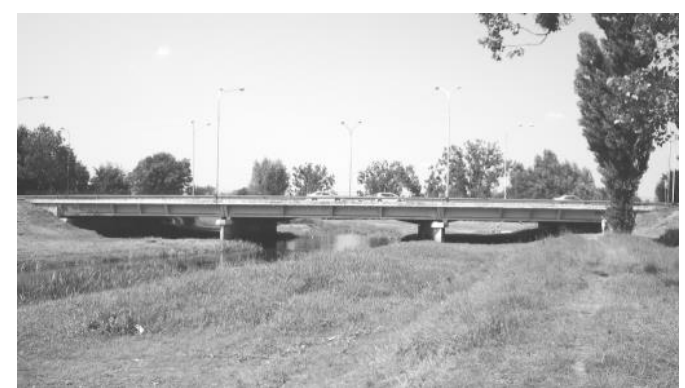

b) Bolesław Krzywousty Bridge

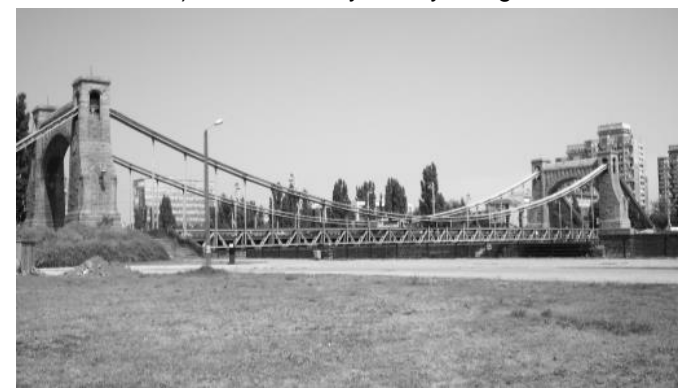

d) Grunwaldzki Bridge

Fig. 1. Views of bridges (Photographed by A. Duchaczek)

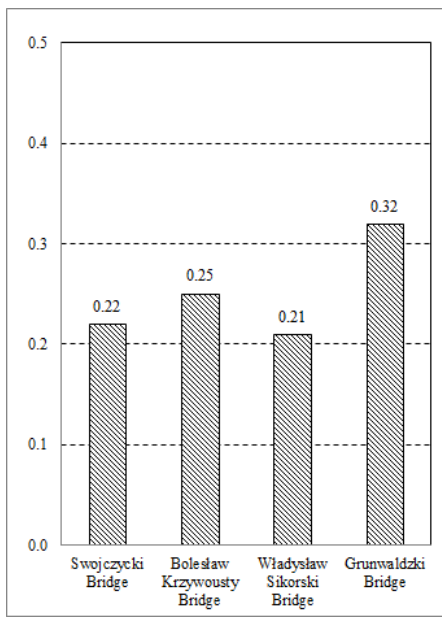

(a)

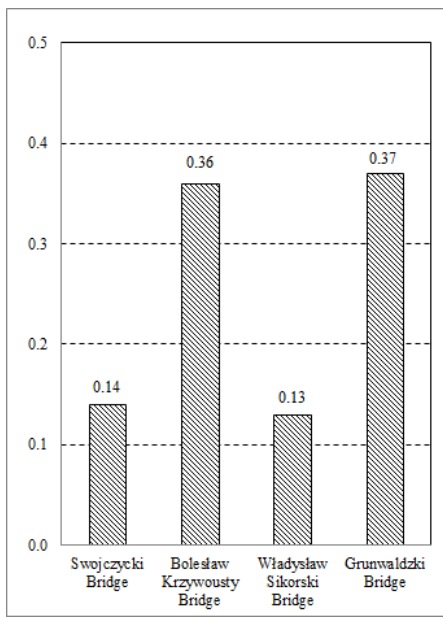

(b)

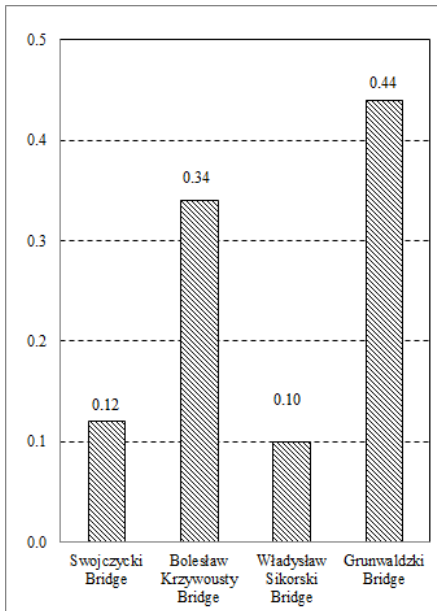

(c)

Fig. 2. The value of the: a) probability $p_{i}$, b) consequence $c_{i}$ and c) risk $R_{i}$, of damage of selected bridges

Occurrence of an alternative passage, expressed in percentage was the five criterion (criterion $C$ C5). It was proposed to adopt $0 \%$ value in the case of a lack of an alternative passage and when there is a passage meeting ideal technical conditions for the original facility, its assumed value is $100 \%$. It is justified by the fact that a possibility to use an alternative detour of a water or terrain obstacle significantly decreases consequences of a damage of the original bridge facility [4].

\section{An example of risk evaluation of a bridge facility dam- age with consideration for terrorist attacks}

The goal of the authors practical presentation of the proposed method of determination of risk of a bridge facility damage without any reference to a particular part of the country, this is why the selected bridges vary in construction type and location. In the work four bridges $(V 1-V 4)$ located near Wrocław
(Poland, Central Europe) were analysed. The selected bridges met the requirements of the assumed characteristics (Fig 11).

First of all it was necessary to assess the probability of damaging the selected bridge facilities. Table 1 presents data (parameters) of the selected bridges used in the analysis of their damage probability. The analysis of probability of damaging bridge facilities was conducted on the basis of five criteria, such as: object security $(C P 1)$, traffic volume $(C P 2)$, maximum span length (CP3), construction material (CP4) and span construction (CP5).

Table 2 presents criteria weights adopted in the analysis and received using the AHP method. The comparison of five criteria has been conducted by defining the degree of preference of one criterion over the other (matrix $A$ created according to the formula 6). All calculations were performed according to the formulas described in section 3.1 of this article. Subjective 
Tab. 1. Data of the selected bridges used in the analysis of their damage probability and damage consequences [40]

\begin{tabular}{|c|c|c|c|c|c|}
\hline \multirow{2}{*}{\multicolumn{2}{|c|}{ Assessment criterion }} & \multicolumn{4}{|c|}{ Bridge name (Variant) } \\
\hline & & \multirow{2}{*}{$\frac{\text { Swojczycki }}{(V 1)}$} & \multirow{2}{*}{$\begin{array}{c}\begin{array}{c}\text { Bolesława } \\
\text { Krzywoustego }\end{array} \\
(\text { V2) }\end{array}$} & \multirow{2}{*}{$\begin{array}{c}\text { Władysława } \\
\text { Sikorskiego } \\
\text { (V3) }\end{array}$} & \multirow{2}{*}{$\frac{\text { Grunwaldzk }}{(\text { V4) }}$} \\
\hline & & & & & \\
\hline \multicolumn{6}{|c|}{ The parameters used in the analysis of their damage probability (linguistic variables) } \\
\hline Object security & $(C P 1)$ & Poor & Good & Good & Very good \\
\hline Traffic volume & $(C P 2)$ & Low & Very high & High & Very high \\
\hline Maximum span length & (CP3) & Long & Short & Long & Very long \\
\hline Construction material & $(C P 4)$ & Reinforced concrete & Reinforced concrete & Steel & Steel \\
\hline Span construction & (CP5) & Arch & Beam & Truss & Suspended \\
\hline \multicolumn{6}{|c|}{ The parameters used in the analysis of their damage consequences (numerical variables) } \\
\hline $\begin{array}{l}\text { Maximum span length } \\
(\mathrm{m})\end{array}$ & $(C C 1)$ & 48 & 21 & 46.5 & 112.5 \\
\hline $\begin{array}{c}\text { Number of lanes on } \\
\text { the bridge }\end{array}$ & $(C C 2)$ & 2 & 4 & 2 & 4 \\
\hline $\begin{array}{l}\text { Number of indirect } \\
\text { pillars }\end{array}$ & $(C C 3)$ & 3 & 2 & 1 & 0 \\
\hline $\begin{array}{c}\text { Traffic volume * } \\
\text { (vehicle/day) }\end{array}$ & $(C C 4)$ & 10000 & 30000 & 20000 & 30000 \\
\hline $\begin{array}{c}\text { Alternative passage } \\
(\%)\end{array}$ & $(C C 5)$ & 60 & 10 & 80 & 70 \\
\hline
\end{tabular}

* The data in Table 1 related to traffic volume (CC5) are only rough estimates.

Tab. 2. Criterion weights adopted in the analysis

\begin{tabular}{|c|c|c|c|c|c|c|c|}
\hline \multirow{2}{*}{\multicolumn{2}{|c|}{ Specification }} & \multicolumn{5}{|c|}{ Number of criteria } & \multirow{3}{*}{$\begin{array}{c}\text { Weight value } w_{i} \\
0.20\end{array}$} \\
\hline & & \multirow{2}{*}{$\begin{array}{l}C P 1 \\
1.00\end{array}$} & \multirow{2}{*}{$\begin{array}{l}C P 2 \\
0.60 \\
\end{array}$} & \multirow{2}{*}{$\begin{array}{l}C P 3 \\
0.80 \\
\end{array}$} & \multirow{2}{*}{$\begin{array}{l}C P 4 \\
5.00 \\
\end{array}$} & \multirow{2}{*}{$\begin{array}{l}\text { CP5 } \\
0.80\end{array}$} & \\
\hline Object security & CP1 & & & & & & \\
\hline Traffic volume & CP2 & 1.67 & 1.00 & 1.00 & 6.00 & 0.80 & 0.26 \\
\hline $\begin{array}{l}\text { Maximum span } \\
\text { length }\end{array}$ & CP3 & 1.25 & 1.00 & 1.00 & 3.00 & 0.90 & 0.22 \\
\hline $\begin{array}{c}\text { Construction } \\
\text { material }\end{array}$ & $\mathrm{CP} 4$ & 0.20 & 0.17 & 0.33 & 1.00 & 0.25 & 0.06 \\
\hline $\begin{array}{c}\text { Span } \\
\text { construction }\end{array}$ & CP5 & 1.25 & 1.25 & 1.11 & 4.00 & 1.00 & 0.26 \\
\hline
\end{tabular}

evaluation expressed in priority value showed that traffic volume $(C P 2)$ and span construction (CP5) will have the biggest influence on construction security.

Table 3 presents evaluations of particular variants (bridge types) according to the criterion $C P 1$ (object security). The comparison of four variants (bridges) has been conducted by defining the degree of preference of one variant over the other (matrix $A$ created according to the formula (6). Also in this case, all calculations were performed according to the formulas described in section 3.1 of this article.

Table 4 presents summary of all evaluations of particular variants (bridge types) according to all (five) adopted criteria (CP1CP5). In this case Table 4 also presents priority values for each analysed variant. Table 4 presents only the final results of the conducted analyses. A detailed calculation procedure of probability of damage to bridges for the similar example (six objects and six criteria) was described by Duchaczek and Skorupka in earlier work [3].
The Table 4 and Fig 2 a present also the obtained final calculation results, i.e. values of the AHP index. The calculations explicitly showed that the facility in the case of which there is the highest probability of a terrorist attack is Grunwaldzki Bridge (V4), next Bolesława Krzywoustego Bridge (V2).

Analysing the consistency ratio $C R$ values presented in Table 5 it can be concluded that assessments of particular solutions were very coherent because the consistency ratio $C R$ value was much lower than $10 \%$.

Next consequences of damaging selected bridge facilities were analysed. The work presents possible applications of the Bellinger method in consequences assessment of these bridge facilities. The analysis of consequences of damaging bridge facilities was conducted on the basis of five criteria, such as: span length $(C C 1)$, number of lanes on a bridge $(C C 2)$, number of indirect pillars $(C C 3)$, traffic volume $(C C 4)$ and alternative passage occurrence $(C C 5)$. The data in Table 1 related to traffic volume (CC5) are only rough estimates (Table 1 . 
Tab. 3. Evaluation of bridges according to criterion $C P 1$ (object security)

\begin{tabular}{|c|c|c|c|c|c|c|}
\hline \multicolumn{2}{|c|}{ Bridge name (Variant) } & V1 & V2 & V3 & V4 & Priority $(C P 1)$ \\
\hline $\begin{array}{l}\text { Bolesława } \\
\text { Chrobrego }\end{array}$ & V1 & 1.00 & 4.00 & 4.00 & 8.00 & 0.59 \\
\hline $\begin{array}{c}\text { Bolesława } \\
\text { Krzywoustego }\end{array}$ & V2 & 0.25 & 1.00 & 1.00 & 4.00 & 0.18 \\
\hline $\begin{array}{l}\text { Władysława } \\
\text { Sikorskiego }\end{array}$ & V3 & 0.25 & 1.00 & 1.00 & 4.00 & 0.18 \\
\hline Grunwaldzki & V4 & 0.13 & 0.25 & 0.25 & 1.00 & 0.05 \\
\hline
\end{tabular}

Tab. 4. Assessment of particular variants according to five criteria and the obtained values of weight coefficients

\begin{tabular}{|c|c|c|c|c|c|c|c|}
\hline \multirow{2}{*}{\multicolumn{2}{|c|}{ Bridge name (Variant) }} & \multicolumn{5}{|c|}{ Priority value for particular criteria } & \multirow{3}{*}{$\begin{array}{c}\text { AHP index } \\
0.22\end{array}$} \\
\hline & & \multirow{2}{*}{$\begin{array}{l}C P 1 \\
0.59 \\
\end{array}$} & \multirow{2}{*}{$\begin{array}{l}C P 2 \\
0.06 \\
\end{array}$} & \multirow{2}{*}{$\begin{array}{l}\text { CP3 } \\
0.11 \\
\end{array}$} & \multirow{2}{*}{$\begin{array}{l}C P 4 \\
0.40\end{array}$} & \multirow{2}{*}{$\begin{array}{l}\text { CP5 } \\
0.16\end{array}$} & \\
\hline Swojczycki & V1 & & & & & & \\
\hline $\begin{array}{c}\text { Władysław } \\
\text { Sikorski }\end{array}$ & V3 & 0.18 & 0.13 & 0.30 & 0.10 & 0.27 & 0.21 \\
\hline Grunwaldzki & V4 & 0.05 & 0.37 & 0.51 & 0.10 & 0.36 & 0.32 \\
\hline
\end{tabular}

Tab. 5. Results credibility is checked by calculation

\begin{tabular}{|c|c|c|c|c|c|}
\hline \multirow{2}{*}{ Parameter } & \multicolumn{5}{|c|}{ Number of criteria } \\
\hline & CP1 & $C P 2$ & CP3 & CP4 & CP5 \\
\hline Consistency Index $\mathrm{Cl}$ & 0.03 & 0.02 & 0.01 & 0.00 & 0.00 \\
\hline
\end{tabular}

Tab. 6. The desired change of numerical values for particular criteria

\begin{tabular}{|c|c|c|c|c|c|}
\hline \multirow{2}{*}{ Specification } & \multicolumn{5}{|c|}{ Number of criteria } \\
\hline & CC1 & CC2 & CC3 & CC4 & CC5 \\
\hline $\begin{array}{l}\text { Desired criterion } \\
\text { value (stimulant) }\end{array}$ & 112.5 & 4 & 3 & 30000 & 10 \\
\hline $\begin{array}{l}\text { Undesired criterion } \\
\text { value (destimulant) }\end{array}$ & 21 & 2 & 0 & 10000 & 80 \\
\hline $\begin{array}{c}\text { Weight value of } \\
\text { particular criteria }\end{array}$ & 0.25 & 0.20 & 0.15 & 0.25 & 0.15 \\
\hline
\end{tabular}

Tab. 7. Results of risk assessment calculations for selected bridge facilities damage

\begin{tabular}{cccc}
\hline Variant (bridge) & Joint assessment $o_{i}$ & Consequence $c_{i}$ & $\begin{array}{c}\text { Damage risk of a bridge } \\
\text { facility } R_{i}\end{array}$ \\
\hline V1 & 26.66 & 0.14 & 0.12 \\
\hline$V 2$ & 70.00 & 0.36 & 0.22 \\
\hline V3 & 24.47 & 0.13 & 0.25 \\
\hline V4 & 72.14 & 0.37 & 0.10 \\
\hline
\end{tabular}


Simultaneously a desired direction of numerical changes was adopted for particular criteria, it is presented in Table 6 . In the analysed example the top and bottom change boundary for particular criteria were equal to equal extreme values of particular criteria. Table 6 presents also weights accepted for particular criteria.

Table 7 presents the determined joint assessments $o_{i}$ obtained as a result of calculations for the analysed case. The conducted analysis shows that from the point of view of decision maker's preferences (weights' values) and the adopted criteria, the highest joint assessment $o_{i}$ was given to Grunwaldzki Bridge (V4).

This article presents only the final results of the conducted analyses. A detailed calculation procedure of consequences of damage to bridges for the similar example (six objects and seven criteria) was described by Duchaczek and Skorupka in earlier work [4].

Taking into account the fact that it was assumed that consequence $c_{i}$ of a damage of particular bridges was a value in the range $<0 ; 1>$, thus the obtained values of the joint assessment $o_{i}$ had to be appropriately modified. The determination of consequence $c_{i}$ for particular bridges was conducted using the following expression [4]:

$$
c_{i}=\frac{o_{i}}{O_{w}}
$$

where $O_{w}$ is the sum of all joint assessments $o_{i}$, calculated as:

$$
O_{w}=\sum_{i=1}^{n} o_{i} .
$$

During the analysis of the data presented in Table 7 and Fig $2 \mathrm{p}$ it was found out that after the conducted calculations the Grunwaldzki Bridge (V4) certainly still has the highest value of consequence. This means that in the assumed boundary conditions a damage of this bridge would cause the most serious consequences for inhabitants of the analysed area of a country.

The Table 7 and Fig 2re present also risk calculations results for selected bridge facilities conducted using dependencies (Eq. (1)) and (Eq. (2)). Analysing the results presented in Fig2 it was found out that the highest damage risk was related to variant V4, i.e. Grunwaldzki Bridge. The conducted analyses indicated that this bridge is much more exposed to terrorist attacks than Bolesława Krzywoustego Bridge (V2), however, the damage risk of the other bridge facilities ( $V 1 \mathrm{i} V 3)$ is even several times lower.

Currently the presented results and the results of earlier calculations [3, 4] explicitly showed that the value of risk of the damage to bridge $R_{i}$ depends on the number of analyzed bridges and the number of the adopted criteria.

\section{Conclusions}

The use of the described method will make it possible to quantify risk of bridge facilities damage in the aspect of potential terrorist attacks. The AHP method was used in the procedure of risk assessment (to assess the probability of occurrence of a terrorist attack) and the Bellinger method (to assess consequences of a bridge facility damage). This approach to the problem certainly does not exclude entirely subjective expert assessments, however, it significantly facilitates their task. The most important advantage of the analyses presented in this work is the fact that the adopted decision can be explained in a scientific way and not only referred to somebody's knowledge and experience.

The example presented in this article showed the possibility to use multi-criteria optimisation methods to solve the subjective problem. However, objectivity of the conducted analyses depends on the quantity and "quality" of adopted criteria, which means that it depends on the knowledge of the person conducting analyses. Bridge facilities have various constructions and due to this accepting a fixed and limited number of criteria taking into account their construction is practically impossible. Undoubtedly too many criteria will make it difficult to conduct analyses and will limit them to a narrow group of experts, at the same time it will not guarantee "better" results.

The authors realize that the issue discussed in this paper does not cover all aspects risk assessment of bridge facilities in the aspect of potential terrorist attacks, however, undoubtedly it a continuation and interesting elaboration of subjects discussed in scientific centres all over the world.

The presented method of risk assessment of bridge facilities in the aspects of terrorist attacks, based on the AHP method and the Bellinger method, can be used also in widely understood civil engineering [11, 13, 22, 23] and civil engineering logistics [34].

\section{References}

1 Bellinger B, Multidimensionale Bewertung und Bestgestalffung von Bankfilialen Sonderabbdruck aus Osterreichisches Bank, 1979. Archiw Jahrgang Heft IV, [in German].

2 Chang D-Y, Applications of the extent analysis method on fuzzy AHP, European Journal of Operational Research, 95(3), (1996), 649-655, DOI 10.1016/0377-2217(95)00300-2

3 Duchaczek A, Skorupka D, Evaluation of Probability of Bridge Damage as a Result of Terrorist Attack, Archives of Civil Engineering, 59(2), (2013), 215-227, DOI 10.2478/ace-2013-0011

4 Duchaczek A, Skorupka D, Bridge Damage Risk Assessment, Journal of Science of the Gen. Tadeusz Kosciuszko Military Academy of Land Forces, 3(169), (2013), 99-109. [in Polish].

5 Ginda G, Forecasting on the Basis of Multi-Attribute Analysis. Forecasting and simulations, http://www.bopis.po.opole.pl/pis06_\{win\}.pdf accessed 2012-04-08, [in Polish].

6 Górny P, Elements of Decision Analysis, The National Defence University Publishing House, Warsaw (Poland), 2004. [in Polish].

7 Hastak M, Aury S, ICRAM-1: Model for International Construction Risk Assessment, Journal of Management in Engineering (ASCE), 16(1), (2000), 59-69.

8 Ignasiak E, Operational Research, The National Economic Publishing House, Warsaw (Poland), 2001. [in Polish].

9 Kahraman C, Cebeci U, Ruan D, Multi-attribute comparison of catering service companies using fuzzy AHP: The case of Turkey, International Jour- 
nal of Production Economics, 87(2), (2004), 171-184, DOI 10.1016/S09255273(03)00099-9

10 Kamyk Z, Szelka J, Sensitivity of Bridge Facilities to Terrorist Attacks, Civil Engineering Archives of the Poznan University of Technology, 4, (2008), 8393. [in Polish].

11 Kapliński O, Janusz L, Three Phases of Multifactor Modelling of Construction Processes, Journal of Civil Engineering and Management, 12(2), (2006), 127-134.

12 Kasprowicz T, Cost-Time Scheduling of Construction Works Execution, J. Infrastructure Planning and Management, 660(IV-49), (2000).

13 Kasprowicz T, Construction Undertakings Engineering, The Institute of Exploitation Technology Publishing; Radom (Poland), 2002. [in Polish].

14 Kastelik-Ginda K, The Use of the AHP Method in the End of School Year Student Classification in the Final Year of Secondary School, wWw. kkastelik.scholaris.pl accessed 2012-04-06, [in Polish].

15 Książek M, A Comparative Analysis of Selected Multi-Criteria Methods of Investment Evaluation, Civil and Environmental Engineering, 2, (2011), 555561. [in Polish].

16 Kogut A, Transport Infrastructure, http://mfiles.pl/pl/index.php/ Infrastruktura_transportowa accessed 2012-03-20, [in Polish].

17 Knight FH, Risk, Uncertainty and Profit, University of Boston Press; Boston, 1921.

18 Lu Z, Shen Y, The Study on Venture Capital Project Appraisal Using AHP-Fuzzy Comprehensive Evaluation Methods, International Journal of Advancements in Computing Technology, 3(8), (2011).

19 Molendowski F, Comparison Testing of the Cob_Pickers Bourgoin JDL $410 D$ and Bourgoin GX406A, Inżynieria Rolnicza (Agricultural Engineering), 10, (2006), 327-333. [in Polish].

20 Ostrega A, Management of Excavations and Areas which were Used as Carbonate Resources Workings on the Example Krzemionki Podgórskie in Krakow; Krakow (Poland), 2004. (PhD thesis) [in Polish].

21 Pfeffer J, Insuarance and Economic Theory, Irvin Inc.; Homewood, Illinois, 1956.

22 Plebankiewicz E, Leśniak A, Overhead costs and profit calculation by Polish contractors, Technological and Economic Development of Economy, 19(1), (2013), 141-161, DOI 10.3846/20294913.2012.763008

23 Połoński M, Pruszyński K, Impact of Baseline Terms on the Course of Critical Paths and Time Buffers in the Modified Goldratt's Method, Archives of Civil Engineering, 59(3), (2013), 313-320, DOI 10.2478/ace-2013-0017

24 Przybyło W, Krężołek S, AHP uses in Civil Engineering, WWw. fema.pl/ mit/PUBLIKACJE_WLASNE/doc/ahpwbsk-olsztyn . doc $\backslash$ T1 $\backslash$ textgreater accessed 2009-02-10, [in Polish].

25 Pyza D, Transportation System and Its Shape in Logistic System of Poland, Scientific Papers of the Warsaw University of Technology, 76, (2010), 113129, www.it.pw.edu.pl/prace-naukowe/z76/pyza.pdf [in Polish, accessed 2012-03-20].

26 Ray JC, Risk-Based Prioritization of Terrorist Threat Mitigation Measures on Bridges, Journal of Bridge Engineering, 12(2), (2007), 140-146, DOI 10.1061/(ASCE)1084-0702(2007)12:2(140)

27 Saaty TL, Deriving the AHP 1-9 Scale from First Principles. ISAHP 2001 proceedings, Bern, Switzerland, 2001.

28 Saaty TL, Vargas L, Models, Methods, Concepts $\mathcal{E}$ Applications of the Analytic Hierarchy Process, International Series in Operations Research \& Management Science, Vol. 34, Kluwer Academic Publishing; Boston, 2001, DOI 10.1007/978-1-4615-1665-1

29 Sean T, Regan, Risk Management Implementation and Analysis, AACE International Transaction (CSC.10.1- CSC.10.7); Orlando, 2003.

30 Skorupka D, Identification and Initial Risk Assessment of Construction Projects in Poland, Journal of Management in Engineering, 24(3), (2008), 120-127, DOI 10.1061/(ASCE)0742-597X(2008)24:3(120)

31 Skorupka D, Method of Construction Projects Risk Assessment. Mocra,
LAP LAMBERT Academic Publishing GmbH \& Co. KG; Saarbrücken, Germany, 2012.

32 Skorupka D, Duchaczek A, Szleszyński A, Optimisation of Selecting Transport Means in Building Materials Depot Logistics, Journal of Science of the Gen. Tadeusz Kosciuszko Military Academy of Land Forces, 4(166), (2012), 137-145. [in Polish].

33 Skorupka D, Duchaczek A, Szleszyński A, Application of Multi-criteria Optimization Methods to the Process of Transportation Means Selection in Warehouse Logistics, Gospodarka materiałowa i Logistyka (Materials Management \& Logistics), 2, (2013), 27-31.

34 Sobotka A, Czarnigowska A, Analysis of Supply System Models for Planning Construction Project Logistics, Journal of Civil Engineering and Management, 11(1), (2005), 73-82.

35 Teknomo K, Analytic Hierarchy Process. Kardi Teknomo's Homepage, http://people.revoledu.com/kardi/tutorial/AHP/AHP.htm 'weblog', accessed 2012-04-06.

36 Willet AH, The Economic Theory of Risk Insurance, University of Pennsylvania Press; Philadelphia, 1951.

37 Wolny M, Support of Management Decisions in an Industrial Enterprise. Multi-Attribute Support of Spatial Organisation of Manufacturing Cells Using the Game Theory, Publishing house of Silesian University of Technology; Gliwice (Poland), 2007. [in Polish].

38 Zhu K-J, Jing Y, Chang D-Y, A discussion on Extent Analysis Method and applications of fuzzy AHP, European Journal of Operational Research, 116(2), (1999), 450-456, DOI 10.1016/S0377-2217(98)00331-2

39 Yang X, Yan L, Zeng L, How to handle uncertainties in AHP: The Cloud Delphi hierarchical analysis, Information Sciences, 222, (2013), 384-404, DOI 10.1016/j.ins.2012.08.019

40 Bridges in Wroctaw, http://pl.wikipedia.org/wiki/Kategoria: Mosty_we_Wroc\%C5\%82awiu accessed 2013-07-06, [in Polish].

41 Mine Related Works and Destructions, Head of Military Engineering Forces, Polish General Staff; Warsaw, 1995. [in Polish].

42 Recommendations for Bridge and Tunnel Security, Federal Highway Administration (FHWA). FHWA-IF-03-036, September, 2003.

43 The Act of 26 April 2007 on Crisis Management, Official Journal of Laws 2007 No. 89 item 590, (2007). [in Polish]. 